\title{
COMPARISON OF ENDOSCOPIC FINDINGS WITH GERD SYMPTOMS SCORE IN ZAGAZIG UNIVERSITY HOSPITALS, EGYPT.
}

\author{
Waleed A. Ismail, Ashraf Khalifa \\ Internal Medicine Department, Zagazig University, Egypt
}

\begin{abstract}
Background: Gastroesophageal reflux disease (GERD) may need repeated endoscopy for diagnosis and follow up, this may concern psychological and financial burden on patient. Aim of the work:The aim of our work was to evaluate the benefit of the FSSG as a useful and a practical tool for diagnosing of GERD patients compared to the endoscopic results. This was mainly to avoid repeated uses of endoscopy for diagnosis and may reduce the medical costs and save the patients time Patients \& Methods: This study was carried out at Zagazig University, Faculty of Medicine, Internal Medicine Department, Gastroenterology and endoscopy unit during the period from June 2015 to December 2015.The subjects were 131 Egyptian patients aged $\geq 18$ year (mean $46.3 \pm 16.8$ year; male/female ratio $1.8 / 1$ ) who presented with symptoms of heartburn, regurgitation and epigastric pain or discomfort. They were scheduled for esophagogastroduodenoscopy. It was done after approval of Local Ethics Committee and patient's consent was obtained. Pre-endoscopy Procedure: Our study depends on a simplified questionnaire for evaluation of the symptoms of GERD called FSSG (Frequency Scale for Symptoms of GERD) which consists of 12 questions; all must be answered by all subjects Endoscopy Procedure: All subjects underwent esophagogastroduodenoscopy. The results of endoscopy were classified and graded according to Los Angeles classification into GERD A, B and C according to the severity of the endoscopic findings. After that the final endoscopic diagnosis was compared to the predicted diagnosis resulting from the Regression model and Equation. Results: Based on the endoscopic findings, the number of patients with GERD Los Angeles Class A, B and C was 18.3, 15.3 and $6.9 \%$ respectively. Clinical obesity patients were 3 distributed as duodenal ulcer $(\mathrm{DU})=2$ and GERD $\mathrm{B}=1$ patient. Overweight patients were 58 distributed as gastric ulcer $(\mathrm{GU})=13, \mathrm{DU}=7$, functional dyspepsia $(\mathrm{NUD})=14$, GERD A $=8$, GERD B $=8$ and GERD C $=8$ patients. Normal weight patients were 63 distributed as $\mathrm{GU}=14, \mathrm{DU}=11, \mathrm{NUD}=11$, GERD $\mathrm{A}=16$, GERD B $=10$ and GERD C $=1$ patients. Underweight patients were 7 distributed as $\mathrm{DU}=1, \mathrm{GU}=2, \mathrm{NUD}=3$, GERD A $=0$, GERD B $=1$ and GERD C $=0$ patients. Usage of the FSSG questionnaire with Regression Model help us to predict strongly GERD A by $95.8 \%$, also GERD B by $95 \%$ and weakly predict DU by $81.8 \%$, GERD C by $77.7 \%$, GU by $60.7 \%$ and NUD by $50 \%$.Conclusion: Noninvasive assessment tool FSSG questionnaire was useful for objective evaluation of symptoms in GERD patients and avoid repeated endoscopic examination which is undesirable in terms of medical costs and the burden on the patient and save our developing country efforts and resources.
\end{abstract}

Corresponding Author

Waleed A. Ismail $\quad$ Received: June 2016

E-mail:waleed.fattah@yahoo.com

Tel. No.:01283257001

Accepted: July 2016

\section{INTRODUCTION}

A condition in which the liquid content of the stomach regurgitates (backs up or refluxes) into the esophagus defined as gastroesophageal reflux disease and commonly referred to GERD or acid reflux. Although visible signs of inflammation occur in a minority of patients the liquid can inflame and damage the lining of the esophagus ${ }^{[1]}$. The regurgitated liquid usually contains acid and pepsin that are secreted by the stomach and may contain bile that has backed-up into the stomach from the duodenum. Acid is believed to be the most injurious component of the refluxed liquid.
The role of pepsin and bile in the production of esophageal inflammation and damage is not as clear as the role of acid ${ }^{[2]}$.

Despite this, a cure for the disease has remained elusive and the natural history of the disease remains uncertain. For example, some complications such as esophageal strictures have decreased in prevalence in some countries but the most troubling of the complications of reflux disease (esophageal adenocarcinoma) continues to increase at an alarming rate ${ }^{[2]}$.

Because limited long-term data on natural history are available prior to the widespread availability of acid inhibitory 
agents, the natural history of reflux disease remains uncertain ${ }^{[3]}$. Prior use of nonsteroidal anti-inflammatory drugs smoking, excess body weight and gastrointestinal and cardiac conditions were associated with increased diagnosis of gastro-esophageal reflux disease ${ }^{[4]}$.

A higher frequency of symptoms like heartburn, regurgitation and epigastric pain (greater than 3 times per week) and a long duration of symptoms further increased the risk of GERD ${ }^{[5]}$.

Less is known about spontaneous exacerbations and remissions of the disease. Indirect evidence does suggest that some patients may have troublesome symptoms intermittently ${ }^{[6]}$.

Gastroesophageal reflux disease may need repeated endoscopy for diagnosis and follow up, this may concern psychological and financial burden on patient. So we need a simple, accurate and easy tool to diagnose and follow up these patients without using endoscopy. Upper GI endoscopy is to identify esophageal erosions, the hall-mark feature of erosive reflux disease. New studies though document that up to $70 \%$ of patients with esophageal symptoms have normal endoscopic findings in the esophagus ${ }^{[7]}$.

Esophageal reflux monitoring is the gold standard used to quantify esophageal acid exposure in patients with reflux symptoms and normal endoscopic findings, part of preoperative evaluation in patients planned for anti-reflux and inpatients with persistent reflux symptoms despite acid suppressive therapy ${ }^{[1]}$.

In clinical gastroesophageal reflux and dyspepsia trials, symptoms evaluation by questionnaires have been recommended as the primary outcome measures. Questionnaires should have proven reliability, validity, and responsiveness, and may assess the frequency and/or severity of dyspepsia symptoms ${ }^{[8]}$.

Unidimensional questionnaires contain items concerning a single aspect of dyspepsia, such as symptom severity, whereas multidimensional instruments assess multiple aspects of the condition, usually symptoms and quality of life. Global scales use a single question to rate the overall severity of the condition. Questionnaires must undergo prior validation for three characteristicsreliability, validity, and responsiveness before they are used in clinical trials ${ }^{[9]}$.

Reliability is the ability of an instrument to give the same result in response to the same clinical condition on different occasions ${ }^{[10]}$. Validity refers to whether the questionnaire is actually measuring what it is designed to measure [10]. Responsiveness describes whether the questionnaire is capable of detecting changes in a condition over time, which might reflect therapeutic effects ${ }^{[10]}$.

The aim of our work is to evaluate the benefit of the FSSG as a useful and a practical tool for diagnosing of GERD patients compared to the endoscopic results. This is mainly to avoid repeated uses of endoscopy for diagnosis that may reduce the medical costs and save the patients time, and money in our country.

\section{PATIENTS \& METHODS}

This study was carried out at Zagazig University, Faculty of Medicine, Internal Medicine Department, Gastroenterology and endoscopy unit during period from June 2015 to December 2015.The subjects were 131 Egyptian patients aged $\geq 18$ year (mean $46.3 \pm$ 16.8 year; male/female $1.8 / 1$ ) who presented with symptoms of heartburn, regurgitation and epigastric pain or discomfort. They were scheduled for esophagogastroduodenoscopy. It was done after approval of Local Ethics Committee and patient's consent was obtained.

Inclusion criteria: Patients presented with symptoms of heartburn, regurgitation and/or epigastric pain or discomfort: without any exclusion as regarding for age, sex, smoking habits, drug intake, pregnancy and Body Mass Index (BMI). BMI= weight $(\mathrm{kg}) /$ (height (M)) ${ }^{2}$ Less than $20=$ underweight, 20-25 = normal, $25-30=$ overweight an more than $30=$ clinical obesity ${ }^{[11]}$.

Exclusion criteria: Previous surgery of upper gastrointestinal tract e.g. distal or partial gastrectomy. Serious conditions which may change the nature of anatomy or physiology of the stomach and duodenum or affect the diagnosis by the endoscopy according to nature of the condition like: (a) Cardiac problems e.g. recent myocardial infarction.(b). Hematological problems e.g. 
aplastic anemia, low platelet and severely anemic patients. (c) Renal problems e.g. Acute kidney injury or chronic renal failure.(d) liver disease e.g. liver cell failure or cirrhosis. (e) Malignancies

Clinical examination routine laboratory investigations were done including complete blood picture, liver function tests and kidney function tests.

\section{Methods:}

\section{I- Pre-endoscopy Procedure:}

Our study depends on a simplified questionnaire for evaluation of the symptoms of GERD called FSSG (Frequency Scale for Symptoms of GERD) which consists of 12 questions; all must be answered by all subjects. As shown in (table I).

Table I: Frequency Scale for the symptoms of GERD (FSSG) ${ }^{[12]}$

\begin{tabular}{|c|c|c|c|c|c|c|}
\hline \multirow{2}{*}{\multicolumn{2}{|c|}{ Questions }} & \multicolumn{5}{|c|}{ Frequency } \\
\hline & & never & $\begin{array}{c}\text { Occasionall } \\
\mathbf{y}\end{array}$ & $\begin{array}{c}\text { Sometime } \\
\mathrm{s}\end{array}$ & often & always \\
\hline 1 & Do you get heartburn? & 0 & 1 & 2 & 3 & 4 \\
\hline 2 & Does your stomach get bloated? & 0 & 1 & 2 & 3 & 4 \\
\hline 3 & $\begin{array}{l}\text { Does your stomach ever feel heavy } \\
\text { after meals? }\end{array}$ & 0 & 1 & 2 & 3 & 4 \\
\hline 4 & $\begin{array}{l}\text { Do you sometimes subconsciously } \\
\text { rub your chest with your hand? }\end{array}$ & 0 & 1 & 2 & 3 & 4 \\
\hline 5 & Do you ever feel sick after meals? & 0 & 1 & 2 & 3 & 4 \\
\hline 6 & Do you get heartburn after meals? & 0 & 1 & 2 & 3 & 4 \\
\hline 7 & $\begin{array}{l}\text { Do you have unusual (e.g. burning) } \\
\text { sensation in your throat? }\end{array}$ & 0 & 1 & 2 & 3 & 4 \\
\hline 8 & Do you feel full while eating meals? & 0 & 1 & 2 & 3 & 4 \\
\hline 9 & $\begin{array}{l}\text { Do some things get stuck when you } \\
\text { swallow? }\end{array}$ & 0 & 1 & 2 & 3 & 4 \\
\hline & $\begin{array}{l}\text { Do you get bitter liquid (acid) } \\
\text { coming up into your throat? }\end{array}$ & 0 & 1 & 2 & 3 & 4 \\
\hline $\begin{array}{l}1 \\
1\end{array}$ & Do you burp a lot? & 0 & 1 & 2 & 3 & 4 \\
\hline & $\begin{array}{l}\text { Do you get heartburn if you bend } \\
\text { over? }\end{array}$ & 0 & 1 & 2 & 3 & 4 \\
\hline & Total score $=$ & & + & + & & \\
\hline
\end{tabular}

- $2,3,5,8,11$ questions of dyspeptic (dysmotility) symptoms.

- $1,4,6,7,9,10,12$ questions of Acid reflux related symptoms.

- Patients answered (yes) were selected and were assigned scores and also data about name, age, sex, BMI (weight, height), history, obesity, smoking, drugs and pregnancy were collected.

- The score for the five questions concerning dyspeptic (dysmotility) symptoms (DS) and seven questions concerning acid reflux-related symptoms (RS) was estimated.

- Total score were given to each patient.

\section{II-Endoscopy Procedure:}

- All subjects underwent esophagogastroduodenoscopy. The results of endoscopy were classified and graded according to Los Angeles classification into GERD A, B and C according to the severity of the endoscopic findings ${ }^{[13]}$.

- Other endoscopic findings were gastric ulcer (GU), duodenal ulcer (DU), functional dyspepsia (NUD). 
- After that the final endoscopic diagnosis was compared to the predicted diagnosis resulting from the Regression model and Equation.

Statistical Analysis:

Y=Dae:80 w0re08aXallyked according to computerized statistical program SPSS (version 18, SPSS Inc., Chicago, IL, USA).The aim of this analysis is to predict the diagnosis according to the score of the questionnaire previously obtained during history taking prior to upper GI endoscopy.

Regression model $(\mathrm{Y}=\alpha+\beta \mathrm{X})$ is designed to achieve this aim statistically.

Where: $\mathrm{Y}=$ dependent variable (diagnosis), $\alpha=$ regression intercept $=$ constant

$\beta=$ regression coefficient $=$ slope, $X=$ independent variable $=$ score

- Code number was assigned to each predicted disease from 1 to 6 according to the ascending results of total score of the questionnaire as follow:

- NUD 1-8, GU 9-17, ,DU 18 - 25

- GERD A 26 - 34 , GERD B $35-42$, GERD C $43-48$

- The code number as follow:

- $\mathrm{NUD}=0-1, \mathrm{GU}=1-2, \mathrm{DU}=2-3$

- GERD $\mathrm{A}=3-4$, GERD $\mathrm{B}=4-5$, GERD $\mathrm{C}=5-6$

The total score is recorded and expressed through (the Regression Model and Equation): $Y=0.280+0.108$ (X).

- For examples:

- Example (1): example is compatible with the Regression Model and equation.
- If the total score (X) were 41

- And the endoscopic findings were

GERD B with code number from 4 to 5 .

- According to the Regression Model

$\mathrm{Y}=0.280+0.108(\mathrm{X})$

$\mathrm{Y}=0.280+" 4.428 "$

$\mathrm{Y}=4.708$

- Then the predicted diagnosis were at the range of GERD B (4-5)

- The cases were compatible with the Regression Model and equation.

Example (2): example was not compatible with Regression Model and equation.

- $\quad$ If the total score (X) were 29

- And the endoscopic findings were antral gastritis with code number from 1 to 2 .

- According to the Regression Model

$$
\begin{aligned}
& \mathrm{Y}=0.280+0.108 \mathrm{X}(29) \\
& \mathrm{Y}=0.280+" 3.132 "
\end{aligned}
$$

$\mathrm{Y}=3.412$

- Then the predicted diagnosis was at the range of GERD A (3-4).

- The cases were not compatible with the Regression Model and equation.

- This was due to patient hyper estimation or hypo estimation of the questionnaire which leaded to this incompatibility.

\section{Results}

The number of the patients in the current study with heartburn, regurgitation, epigastric pain and discomfort was 131, of which the male patients were $64.9 \%$, while the female patients were $35.1 \%$. The age of the patients ranged from 18 to 83 years. The body mass index of the patients was $24.2 \pm 3.2$. 
Table 1: Demographic distribution of risk factors among studied patients:

\section{NUD GU DU GERD A GERD B GERD C}

\begin{tabular}{lcccccc}
\hline Smoking & 11 & 15 & 13 & 13 & 9 & 7 \\
\hline Pregnancy & 4 & 1 & 0 & 1 & 0 & 0 \\
\hline Drugs & 8 & 13 & 9 & 7 & 8 & 1 \\
\hline
\end{tabular}

Drug like Non-steroidal anti-inflammatory drugs (NSAIDs), cortisone, bronchial asthma drugs

Table 2: Endoscopic diagnosis among studied patients.

\begin{tabular}{lll}
\hline Diagnosis & No. & $\%$ \\
\hline Non ulcer disease (NUD) & 28 & 21.2 \\
\hline Gastric ulcer (GU) & 28 & 21.4 \\
\hline Duodenal ulcer (DU) & 22 & 16.8 \\
\hline GERD & & \\
\hline Los Angeles Class A & 24 & 18.3 \\
\hline Los Angeles Class B & 20 & 15.3 \\
\hline Los Angeles Class C & 9 & 6.9 \\
\hline Total & 131 & 100 \\
\hline
\end{tabular}

Based on the endoscopic findings, the number of patients with NUD, GU and DU was $21.2,21.4$ and $16.8 \%$ respectively. While the number of patients with GERD Los
Angeles Class A, B and C was 18.3, 15.3 and $6.9 \%$ respectively.

There was no significant difference among different endoscopic findings in different ages of patients $(\mathrm{P}=0.49)$.

Table 3: Demographic distribution of Body Mass Index (BMI) among studied patients according to the endoscopic diagnosis.

\begin{tabular}{lcccccc}
\hline BMI & NUD & \multicolumn{1}{l}{ GU } & DU & GERD A & GERD B & GERD C \\
\hline less than 20 & 3 & 1 & 2 & 0 & 1 & 0 \\
\hline $20-25$ & 11 & 14 & 11 & 16 & 10 & 1 \\
\hline $25-30$ & 14 & 13 & 7 & 8 & 8 & 8 \\
\hline More than 30 & 0 & 0 & 2 & 0 & 1 & 0 \\
\hline
\end{tabular}

Clinical obesity patients were 3 distributed as $\mathrm{DU}=2$ and GERD $\mathrm{B}=1$ patient

Overweight patients were 58 distributed as $\mathrm{GU}=13, \mathrm{DU}=7, \mathrm{NUD}=14, \mathrm{GERD} \mathrm{A}=8$, GERD $\mathrm{B}=8$ and GERD $\mathrm{C}=8$ patients.
Normal weight patients were 63 distributed as $\mathrm{GU}=14, \mathrm{DU}=11, \mathrm{NUD}=11, \mathrm{GERD} \mathrm{A}=$ 16 , GERD $\mathrm{B}=10$ and GERD $\mathrm{C}=1$ patients. Underweight patients were 7 distributed as $\mathrm{DU}=1, \mathrm{GU}=2, \mathrm{NUD}=3, \mathrm{GERD} \mathrm{A}=0$, GERD $\mathrm{B}=1$ and GERD $\mathrm{C}=0$ patients. 
Table 4: Expected results of endoscopic examination according to the total score of patient's questionnaire using the regression model and equation.

\begin{tabular}{lcccccc}
\hline $\begin{array}{c}\text { Endoscopic } \\
\text { diagnosis }\end{array}$ & $\begin{array}{c}(\mathbf{X}) \\
\text { Total } \\
\text { score }\end{array}$ & $\begin{array}{c}\text { No. of } \\
\text { patients }\end{array}$ & $\begin{array}{c}(\mathbf{Y}) \\
\text { predicted } \\
\text { diagnosis }\end{array}$ & $\begin{array}{c}\text { No. of patients } \\
\text { agree with the } \\
\text { regression } \\
\text { model }\end{array}$ & $\begin{array}{c}\text { No. of patient } \\
\text { disagree with } \\
\text { the model }\end{array}$ & $\begin{array}{c}\text { Success } \\
\text { rate \% }\end{array}$ \\
\hline NUD & $1-8$ & 28 & $0-1$ & 14 & 14 & 50.0 \\
\hline GU & $9-17$ & 28 & $1-2$ & 17 & 11 & 60.7 \\
\hline DU & $18-25$ & 22 & $2-3$ & 18 & 4 & 81.8 \\
\hline GERD A & $26-34$ & 24 & $3-4$ & 23 & 1 & 95.8 \\
\hline GERD B & $35-42$ & 20 & $4-5$ & 19 & 3 & 95.0 \\
\hline GERD C & $43-48$ & 9 & $5-6$ & 6 & & 77.7 \\
\hline
\end{tabular}

- (X) Total score is the result of patient's questionnaire

- (Y) Predicted diagnosis each diagnosis take a code number.

- No. of patient disagree with the model: patient gave hypo estimation or hyper estimation that lead to false predicted diagnosis.

- Success rate $=$ no. of patients agree with regression model / no. of patients for the expected endoscopic diagnosis.x100.

i.e.: success rate of regression model for NUD $=14 / 28 \times 100=50 \%$

Usage of the FSSG questionnaire with Regression Model help us to predict strongly GERD A by $95.8 \%$, also GERD B by $95 \%$ and weakly predict DU by $81.8 \%$, GERD C by $77.7 \%$, GU by $60.7 \%$ and NUD by $50 \%$.

\section{DISCUSSION}

Gastroesophageal reflux is the upward efflux of the stomach's contents into the esophagus. Severity of GERD depends on LES dysfunction as well as type and amount of acid brought up from the stomach and the neutralizing effect of saliva ${ }^{[14]}$.

The global burden of GERD is increasing, data from 28 studies ofGERD prevalence (defined by either typical symptoms at least onceweekly or the Montreal definition) indicate estimates of $18.1-27.8 \%$ inNorth America, 8.8 - 25.9\% in Europe, $2.5-7.8 \%$ in East Asia, $8.7-33.1 \%$ in the Middle East, $11.6 \%$ in Australia and $23 \%$ in South America ${ }^{[15]}$.

The studies of clinical manifestations of GERD have led to the development of the frequency scale for the symptoms of GERD (FSSG) questionnaire that scores the frequency at which patients experience the complaints, and has been shown to be useful in the diagnosis and follow up of GERD ${ }^{[\mathbf{1 2}]}$.

Over use of upper endoscopy contributes to higher health care costs without improving patient outcomes, so for identification of GERD symptoms in every day clinical practice, the questionnaire are developed and used as FSSG $^{[12]}$.

The questions related to 12 symptoms that the patients with GERD complain of most not only heart burn and acid taste but also dyspeptic symptoms such as heavy stomach and feeling full quickly ${ }^{[\mathbf{1 6}]}$.

In our study, there is significant frequency of heartburn, regurgitation and epigastric pain or discomfort in male than female and older age than younger age and this in agreement of the findings of El-Serag and Sonnenberg (1997) [17]

Our study revealed a tendency of heartburn, regurgitation and epigastric pain or discomfort in smokers than nonsmoker. But the result of other study showed controversial associations. Nevertheless, smoking is not considered a major risk factor for GERD despite the impact if both smoking and nicotine on major GERD pathophysiologic factor ${ }^{[18]}$.

We found that there was significant frequency of heartburn, regurgitation and epigastric pain or discomfort in overweight and obese patients than normal weight.

El Serag (2008) studied the role of obesity in GERD related disorders. The abdominal obesity promoted GERD by elevating intraabdominal pressure, which increases reflux and the hiatus hernia development ${ }^{[19]}$.In the 
other hand the GERD symptoms decreased markedly by weight reduction ${ }^{[20]}$.

We found that there was significant frequency of heartburn, regurgitation and epigastric pain or discomfort in pregnant women. As Baron and Richter (1992) proved that pregnancy is the most common condition predisposing to GERD and it is associated with symptomatic GERD (typically heart burn) rather than esophagitis ${ }^{[21]}$.On the opposite, many researchers considered GERD symptoms that occur during pregnancy to be normal because heartburn symptom affects more than two thirds of all pregnancies ${ }^{[22]}$.

In our study, there was significant frequency of heartburn, regurgitation and epigastric pain or discomfort in patient using NSAIDs. Katz (1999) proved that NSAIDs cause esophagitis (23). Furthermore, El Serag and Sonnenberg (1997) proved that NSAIDs disrupt tissue resistance and more severe cases of esophagitis might be more common among chronic NSAIDs users ${ }^{[17]}$.

The FSSG contains questions about dyspeptic (dysmotility) symptoms in addition to acid reflux symptoms allowing it to pick up GERD symptoms widely ${ }^{[24]}$. So, in patients with GERD, the FSSG score correlated with the endoscopic severity ${ }^{[25]}$. The results of this Japanese study demonstrated that the FSSG score reflect the endoscopic severity of GERD, supporting our conclusion that Usage of the FSSG questionnaire with Regression Model helps us to predict strongly GERD A by $95.8 \%$, also GERD B by $95 \%$ and weakly predict DU by $81.8 \%$, GERD C by $77.7 \%$, GU by $60.7 \%$ and NUD by $50 \%{ }^{[25]}$. Study of Danjo et al., Demonstrated that FSSG score reflect the endoscopic severity of GERD supporting our result that FSSG score was suitable to predict diagnose of GERD as discussed above ${ }^{[25]}$.

\section{CONCLUSION}

In comparison to invasive maneuvers like endoscopy; there's noninvasive assessment tool FSSG questionnaire, by using the regression model and equation to predict the disease that save the time and money of the patient and this is the main aim of our study. The results of our study correlated strongly with the endoscopic findings in GERD A and B but weak in GERD C, GU,
DU and NUD, suggesting that it may be possible to evaluate and monitoring patients without repeated endoscopy. This questionnaire is useful for objective evaluation of symptoms in GERD patients and avoid repeated examination which in undesirable in terms of medical costs and the burden on the patient and save our developing country efforts and resources

Limitation of the study: Despite the small sample size of this study, our results should encourage further investigations using FSSG questionnaire for objective evaluation of treatment for GERD, such as proton-pump inhibitors.

\section{REFERENCES}

1-Kahrilas PJ: Clinical practice. Gastroesophageal reflux disease. New England Journal of Medicine 2008; 359(16): 1700-1707.

2-Vakil N: Disease definition, clinical manifestations, epidemiology and natural history of GERD. Best Practice and Research Clinical Gastroenterology 2010; 24: 759-764.

3-Hongo M: GERD guidelines workshop report 2002. Ther RES 2003; 24:830-5.

4-DeVault KR, Castell DO: American collage of gastroenterology. Updated guidelines for the diagnosis and treatment of gastro-esophageal reflux disease. Am J Gastroenterology 2005; 100: 190-200.

5-Dent J, El-serag HB, Wallander MA, et al: Epidemiology of gastroesophageal reflux disease: A systematic review. Gut 2005; 54: 710-7.

6-De Jonge PJ, Van Blankenstein M: Risk of malignant progression in patient with barrett's esophagus: a dutch nationwide cohort study. Gut 2010; 59 (8): 1030-6.

7-Tack J, Fass R: Review article: approaches to endoscopic-negative reflux disease: part of the GERD spectrum or a unique acid-related disorder? Aliment Pharmacol Ther 2004; 1(19): 28-34.

8-Veldhuyzen van Zanten SJ, Cleary C, Talley NJ: Drug treatment of functional dyspepsia: A systematic analysis of trial methodology with recommendations for design of future trials 1996.

9-Fitzpatrick R,DaveyC,Buxton MJ: Evaluating patient-based outcome measures for use in clinical trials. Health Technol Assess 1998; 2:1-74.

10- Hankins M: questionnaire discrimination: (re) - introducing coefficient $\delta$, BMC. Medical research methodology 2007; 7:19. 
11-Kouklakis G et al., : Relationship between obesity and Gastroeso-phageal reflux disease. Romanian journal of Gastroenterol 2005; Vol. 14. No, 2, 117-121.

12-Kusano M, Shimoyama Y, Sugimoto S: Development and evaluation of FSSG: frequency scale for the symptoms of GERD. J. Gastroenterol 2004; 39(9): 888-891.

13-Hongo M: Minimal changes in reflux esophagitis: red ones and white ones. J. Gastroenterol 2006; 41:95-9

14-Modlin IM, Moss SF: Symptom evaluation in gastroesophageal reflux disease. J. Clin. Gastroenterol 2008; 42(5): 558-563.

15-El-Serag HB, Sweet S, Winchester CC, Dent J: Update on the epidemiology of gastrooesophageal reflux disease: a systematic review. Gut 2014; 63(6): 871-880.

16-Shimoyama Y, Kusano M, Sugimoto S: Diagnosis of gastroesophageal reflux disease using a new questionnaire. J. Gastroenterol. Hepatol 2005; 20(4): 643-647.

17-El-Serag HB, Sonnenberg A : Associations between different forms of gastro-oesophageal reflux disease. Gut 1997; 41(5): 594-599.

18-Pandolfino JE, Kahrilas PJ: Smoking and gastro-oesophageal reflux disease. Eur. J. Gastroenterol. Hepatol 2000; 12: 837-842.
19-El-Serag H: The association between obesity and GERD: a review of the epidemiological evidence. Dig Dis Sci 2008; 53(9): 2307-2312.

20-Singh M, Lee J, Gupta N: Weight loss can lead to resolution of gastroesophageal reflux disease symptoms: a prospective intervention trial. Obesity (Silver Spring) 2013; 21(2): 284290.

21-Baron TH, Richter JE: gastroesophageal reflux disease in pregnancy. Gastroenterol Clin North Am 1992; 21 (4):777-791. Review

22-Broussard CN, Richter JE : Treating gastrooesophageal reflux disease during pregnancy and lactation: what are the safest therapy options? Drug Saf 1998; 19(4): 325-337.

23-Katz PO: Chest pain of esophageal origin. Curr.Opin.Gastroenterol 1999; 15 (4) 347-351.

24-Miyamoto M1, Haruma K, Takeuchi K: Frequency scale for symptoms of gastroesophageal reflux disease predicts the need for addition of prokinetics to proton pump inhibitor therapy. J. Gastroenterol. Hepatol 2008; 23(5): 746-751.

25-Danjo A, Yamaguchik K, Fujimotok K: Journal of Gastroenterology and Hepatology 2008; 24:633-638. 